\title{
METHODOLOGICAL FEATURES OF STUDYING THE INTERESTS OF THE SUBJECTS OF PROPERTY RIGHTS
}

\author{
Andrey V. Ryzhik \\ Vitebsk State University named after P. M. Masherov, Vitebsk, Belarus
}

Introduction: the problem of identifying the features of studying the interests of the subjects of property rights is of great methodological importance. The question of what are the specifics of the study of a particular scientific problem is the key one that sets the beginning of the entire process of scientific knowledge. The purpose of the study: to identify the features of studying the legal institute of the interests of the subjects of property rights. Methods: the research involved both general methods of scientific knowledge and private law methods, namely, formal legal, the method of interpretation of legal norms, comparative legal analysis. Results: the problems of the interests of the subjects of property rights were studied from different conceptual and methodological positions. Along with the applied and theoretical level, a theoretical and cognitive approach to the study of the interests of property rights subjects is proposed. Special attention is focused on the development of linguistichermeneutical and anthropological components of the modern methodology of cognition. The opinion on the need to take into account these trends in the study of the problems of interests of subjects of various forms of ownership is justified. Conclusions: the features of studying the interests of the subjects of property rights are that highlighting the applied and theoretical levels, it is advisable to focus on the actual theoretical and cognitive core of the study of this legal institute, on the positioning of the content, features of the legal vision, understanding of the legal reality. The models and mechanisms for the realization of the interests of owners in modern Russian law should be studied from a philosophical and sociological perspective, as well as from the perspective of the development of modern theoretical jurisprudence. One of the current trends in the field under study is the strengthening of the role of linguistic and anthropological components in studying the interests of subjects of private, state, and other forms of property. These developing areas of the methodology of knowledge of law open up new opportunities for the interpretation and understanding of legal texts and legal vocabulary.

Key words: interests of owners, property, methodology of legal research, the general methodology of cognition, subject of law.

Citation. Ryzhik A.V. Methodological Features of Studying the Interests of the Subjects of Property Rights. Legal Concept $=$ Pravovaya paradigma, 2021, vol. 20, no. 3, pp. 161-166. (in Russian). DOI: https://doi.org/10.15688/lc.jvolsu.2021.3.24

\section{МЕТОДОЛОГИЧЕСКИЕ ОСОБЕННОСТИ ИССЛЕДОВАНИЯ ИНТЕРЕСОВ СУБЪЕКТОВ ПРАВА СОБСТВЕННОСТИ}

\author{
Андрей Владимирович Рыжик \\ Витебский государственный университет им. П.М. Машерова, г. Витебск, Беларусь
}

Введение: проблематика выявления особенностей исследования интересов субъектов права собственности имеет важное методологическое значение. Вопрос о том, в чем заключается специфика исследования той или иной научной проблемы, является ключевым, задающим начало всему процессу научного познания.

Цель: выявление особенностей исследования правового института интересов субъектов права собственности. Методы: в процессе исследования были задействованы общие методы научного познания и такие частноправовые методы, как формально-юридический, метод толкования правовых норм, сравнительно-правовой анализ. Результаты: проблематика интересов субъектов права собственности была изучена с разных концепту- 
ально-методологических позиций. Наряду с прикладным и теоретическим уровнем предложен теоретико-познавательный подход к изучению интересов субъектов права собственности. Акцентировано внимание на развитии лингвистически-герменевтической и антропологической составляющих современной методологии познания. Обосновано мнение о необходимости учета данных тенденций при исследовании проблем интересов субъектов различных форм собственности. Выводы: особенности исследования интересов субъектов права собственности заключаются в том, что, выделяя прикладной и теоретический уровни, целесообразно делать акцент на собственно теоретико-познавательном ядре исследования данного правового института, на позиционировании содержания, особенностей правового видения, понимания правовой реальности. Модели и механизмы реализации интересов собственников в современном российском праве должны изучаться с философского и социологического ракурсов, а также с позиций развития современного теоретического правоведения. Одной из современных тенденций в изучаемой сфере является усиление роли лингвистической и антропологической составляющих в исследовании интересов субъектов частной, государственной и иных форм собственности. Эти развивающиеся направления методологии познания права открывают новые возможности для толкования и осмысления юридических текстов и юридической лексики.

Ключевые слова: интересы собственников, собственность, методология правового исследования, общая методология познания, субъект права.

Цитирование. Рыжик А. В. Методологические особенности исследования интересов субъектов права собственности // Legal Concept = Правовая парадигма. -2021 . - T. 20, № 3. - C. 161-166. - DOI: https://doi.org/10.15688/lc.jvolsu.2021.3.24

\section{Введение}

Под теоретико-методологическими принципами авторского правового исследования мы понимаем совокупность используемых познавательных ресурсов, необходимых для: 1) определения содержания и спецификаций его объектно-предметного поля, бытийного, социоисторического контекста; 2) обоснования исходных познавательных гипотез, предопределяющих актуальность, новизну, системность целевых ориентиров и задач познавательной деятельности; 3) выявления проблем, противоречий, тенденций, их выражения научной терминологией и обоснования положений, выводов, их актуальности, теоретической новизны и практической значимости.

Проблематика интересов субъектов права собственности может весьма продуктивно исследоваться с разных концептуально-методологических позиций, в рамках многочисленных научных школ и направлений правоведения $[2 ; 5 ; 7 ; 8 ; 10-13]$. Данная проблематика является весьма актуальной и для исследователей неюридического профиля.

Размывание определенных границ между сегментами научно-познавательных специализаций - характерная тенденция современных социально-гуманитарных наук, с которой, безусловно, следует считаться. Одновременно проявляет себя в теоретико-познавательной социально-гуманитарной сфе- ре и тенденция научно-методологической специализации.

Если мы внимательно вникнем в паспорта научных специальностей, утвержденных ВАК России и Беларуси, то при описании их содержания мы обнаружим признаки этих двух тенденций. При классификации как правовых, так и иных социально-гуманитарных исследований применяются и их уровневые характеристики.

\section{Уровни}

\section{специально-юридических исследований}

Так, С.С. Алексеев выделяет два основных уровня специально-юридических исследований - технико-юридический и философский (общесоциологический). Раскрывая содержание этих уровней познания правовой реальности, С.С. Алексеев пишет: «Специально-юридическая проблематика технико-юридического уровня касается в основном общих вопросов догмы права и юридической техники юриспруденции, то есть таких, которые могут быть “выведены за скобки” специальных наук. Специально-юридическая проблематика философского, общесоциологического уровня - более высокая ступень теоретического освоения правового материала, целиком входящая в единое содержание общей теории права, ступень, на которой и раскрываются основные закономерности права» [9, с. 13]. 
Признавая теоретико-методологическую важность подобного подхода, следует обратить внимание, что в определенном смысле философский, социологический уровень теоретического освоения материала, о котором пишет С.С. Алексеев, может быть отнесен к собственно философской или к социологической предметной области и выступать сферой научных интересов представителей тех или иных философских, социологических научных школ и направлений.

В правоведении большинство юридических проблем, выделяемых в объектно-предметную сферу изучения, могут исследоваться как на технико-юридическом, так и на теоретикоправовом уровнях, при этом термин «техникоюридический уровень» не в полной мере выражает собственно прикладной тип исследования, в том числе и отраслевого характера.

В исследовании права, выделяя прикладной и теоретический уровни, целесообразно делать акцент на собственно теоретико-познавательном ядре исследования правовых, юридических феноменов, на позиционировании содержания, особенностей правового видения, понимания правовой реальности.

Даже в отношении самого понятия «право» исследователи придерживаются диаметрально противоположных точек зрения. Так, Р. фон Иеринг рассматривает право как «политику силы», определяя его как «обозначение условий существования общества путем принуждения» $[10$, с. 130], в то время как Л. Дюги утверждает: «Право не есть политика силы, как учил Иеринг, оно не есть дело государства, оно предшествует ему и возвышается над ним: оно является границей государственной силы, и государство есть не что иное, как сила, отданная на служение праву» $[11$, c. 5].

В современной теории права эти положения творчески развиваются, модифицируются, приобретая свойства собственно правовой системной парадигмальности, теоретико-методологического ядра правосознания и одновременно утрачивая некоторые классические признаки собственно философской, социологической и иной предметной специализации.

Именно таким образом мы понимаем современную теорию права, тенденции, про- тиворечия в ее развитии, естественным компонентом которой и является проблематика нашего исследования. Модели и механизмы реализации интересов собственников в современном российском праве, безусловно, могут изучаться как с философских, социологических, так и иных позиций развития современного теоретического правоведения.

Базовыми квалифицированными признаками правового статуса исследования проблематики правовой природы интересов субъектов собственности являются: 1) фактичность интересов любых субъектов правовых отношений и узаконивание их в нормах действующего права; 2) активное использование в юридической терминологии категорий «интерес», «законный интерес», «институт законного интереса», «механизм правовой реализации интересов»; 3) наличие правовых проблем, противоречий в сфере генезиса, развития, реализации интересов физических и юридических лиц, решение которых обеспечивается преимущественно не экономическими, не политическими, а юридическими средствами.

\section{Методологические основания исследования интересов собственников}

«Принято считать, - писал Д.А. Керимов, - что методология едина для всех наук, но в каждой из них она обретает особенности, обусловленные своеобразием объекта и предмета познания. Именно специфика юридических объектов исследования требует относительно самостоятельного существования методологии права как части общефилософской методологии» [12, с. 15].

Чтобы приступить к предметному, комплексному, конкретному исследованию процедуры, механизмов, интересов собственников, необходимо более четко определиться с теми познавательными ресурсами, которые будут образовывать его методологическое основание, с теми принципами, методами познания, которые позволят в познавательном процессе от общих авторских представлений по поводу права, собственности, интересов собственников переходить к исследованию более конкретных проблем, входящих в предметное поле данного исследовательского проекта. 
Нетрудно понять, на каком этапе находятся познавательно-методологические ресурсы отечественных социально-гуманитарных наук, в том числе и правоведения. Труднее определиться с выбором той методологии, которая позволяет наиболее продуктивно исследовать современные юридические проблемы интересов собственников в системе отечественного права.

На современный методологический плюрализм, отличающийся признаками хаотичности, как мы полагаем, следует взглянуть под углом зрения познавательных принципов преемственности и инновационности. Размышляя о методологических ресурсах правоведения, автор делает акцент на выделении в ней общего и специализированного уровня, полагая, что ряд специальных (частных) методов познания правовых явлений вряд ли нуждается в какой-то новой интерпретации или переоценке. Среди них В.К. Бабаев выделяет социологический, сравнительный, формально-юридический, математический [12, с. 15].

Современные социологические методы в правоведении весьма интенсивно наполняются многими новыми познавательными ресурсами, связанными не только с совершенствованием методик социолого-правовых исследований, с усложнением инструментария, но и с новыми подходами к анализу, к интерпретации первичной социологической информации, в том числе и с использованием познавательной инновации современной герменевтики. Изменения происходят и в методах формального изучения правовых феноменов, где традиционная аналитическая познавательная деятельность дополняется методами синтеза тех или иных правовых реалий, на которые ранее не обращалось должного внимания.

Не остаются неизменными и формально-юридические методы исследования правовых феноменов. Классический пример формально-методологического уклона в исследовании правовых феноменов - предельно формализованный подход к осмыслению бытия правовой нормы, когда в конкретной норме права, отражающей те или иные жизненные процессы, способы их регулирования, исследователь не замечает содержания, видя лишь ее формально-атрибутивные универсальные признаки гипотетичности, диспозитивности, санкционированности.

Размышляя о проблематике правовой нормативности, Г.В. Мальцев писал, что необходимо понять, «что есть само право (совокупность норм либо нормы и что-то еще), что такое норма как родовое понятие, общее для всех ее отдельных видов и подвидов, и, наконец, какие моменты и качества конституируют специфическую норму права. Все это принадлежит к числу дискуссионных проблем, относительно которых мы не обладаем достаточными знаниями.

Откуда, например, проистекает убеждение, что идеологический тезис, работающий в системе права, не может быть нормативным? Очевидно, из нежелания видеть, что юридическая норма есть лишь частица огромного и разнообразного мира социальных норм, а также из традиции, свойственной юристам разных эпох и стран, конструировать представление о норме исключительно на основе наблюдений над правовым поведением. Это привело к невероятному сужению самого понятия нормы, сведению его к чистым случаям, допускающим схематизацию по типу “если - то”, “классическую” структуру элементов “гипотеза, диспозиция, санкция". В результате юристы постепенно усвоили привычку без долгих размышлений отказывать нормам, не удовлетворяющим набору этих весьма узких формальных требований, в юридических качествах. Напомним, что нормативным можно считать всякое высказывание о должном в поведении человека и порядке вещей, устраиваемом действиями людей, если оно, это высказывание, выражается в императивной форме (то есть в виде повеления, команды, задания), выступает в качестве побуждения к действию» [13, с. 687].

По сути, в этом положении Г.В. Мальцев намечает теоретико-методологический ориентир в современном понимании и правовой нормативности и содержания формально-юридического метода познания, который следует творчески применять лишь в единстве с методом, акцентирующим внимание исследователя на содержание правовой нормативности. 
Тенденции современной методологии исследования интересов субъектов права собственности

В современном отечественном правоведении с особой остротой и интенсивностью проходят дискуссии, предметом которых являются проблемы характера, меры изменений общей методологии познания, именуемой то общефилософской, то общенаучной, то социально-гуманитарной. В этих дискуссиях рядом авторов обосновывается тезис о возникновении новой - постклассической - методологии, или эпистемологии. Его обоснованию, в частности, посвящена весьма содержательная монография И.Л. Честнова «Постклассическая теория права» [14].

В предисловии к этой работе, ставя вопрос о том, что может предложить постклассическая эпистемология теории права, автор отвечает: «На мой взгляд - прежде всего, применение к описанию и объяснению юридической реальности трех “поворотов” в гуманитарном знании: лингвистического, антропологического и прагматического. Отсюда следует вывод, что право - это текст (в постструктуралистской трактовке этого термина), создаваемый человеком и воспроизводимый действиями и ментальными представлениями людей. Тем самым право - это не статичная структура, редуцируемая либо к безличностному индивиду (методологический индивидуализм теории естественного права), либо к воле законодателя (юридический позитивизм), либо к основной норме (нормативизм в праве), а процесс воспроизведения правовой реальности» $[14$, с. 13].

Автор справедливо указывает на развитие лингвистически-герменевтической и антропологической составляющих современной методологии познания. По сути, антропологический поворот означает презумпцию человечности, гуманистичности современной правовой реальности. Данные тенденции следует учитывать и при исследовании проблем интересов субъектов различных форм собственности.

\section{Выводы}

Подводя итог вышесказанному, отметим, что особенности исследования интересов субъектов права собственности заключаются в следующем. Выделяя прикладной и теоретический уровни, целесообразно делать акцент на собственно теоретико-познавательном ядре исследования данного правового института, на позиционировании содержания, особенностей правового видения, понимания правовой реальности. Модели и механизмы реализации интересов собственников в современном российском праве должны изучаться с философского и социологического ракурсов, а также с позиций развития современного теоретического правоведения.

Базовыми основами исследования проблематики правовой природы интересов субъектов права собственности являются: 1) фактичность интересов любых субъектов правовых отношений и узаконивание их в нормах действующего права; 2) активное использование в юридической терминологии категорий «интерес», «законный интерес», «институт законного интереса», «механизм правовой реализации интересов»; 3) наличие правовых проблем, противоречий в сфере генезиса, развития, реализации интересов физических и юридических лиц, решение которых обеспечивается преимущественно не экономическими, не политическими, а юридическими средствами.

Одной из последних наметившихся тенденций в изучаемой сфере является усиление роли лингвистической и антропологической составляющих в исследовании интересов субъектов частной, государственной и иных форм собственности. Данные направления современной методологии познания права открывают новые возможности для толкования и осмысления юридических текстов и юридической лексики.

\section{СПИСОК ЛИТЕРАТУРЫ}

1. Алексеев, С. С. Общая теория права : учеб. / С. С. Алексеев. - 2-е изд. - М. : Велби ; Проспект, 2009. -565 c.

2. Алексеев, С. С. Право собственности. Проблемы теории / С. С. Алексеев. - М. : Норма, 2008. -239 с.

3. Дюги, Л. Социальное право, индивидуальное право и преобразование государства / Л. Дюги. - М., 1909. $-148 \mathrm{c}$.

4. Иеринг, Р. фон Интерес и право / Р. фон Иеринг. - Ярославль : Тип. Губ. зем. управы, 1880. $268 \mathrm{c}$. 
5. Камышанский, В. П. Право собственности: пределы и ограничения / В. П. Камышанский. - М. : Юнити-Дана : Закон и право, 2000. - 303 с.

6. Керимов, Д. А. Методологические функции философии права / Д. А. Керимов // Государство и право. - 1995. - № 9. - С. 15-22.

7. Кузьмина, А. В. Категория «интерес» в философии и праве / А. В. Кузьмина. - М. : Юрид. лит., 2009. -192 c.

8. Малько, А. В. Законные интересы как правовая категория / А. В. Малько, В. В. Субочев. СПб. : Юрид. центр Пресс, 2004. - 359 с.

9. Мальцев, Г. В. Социальные основания права / Г. В. Мальцев. - М. : Норма, 2007. - 800 с.

10. Мозолин, В. П. Право собственности в Российской Федерации в условиях перехода к рыночной экономике / В. П. Мозолин. - М. : ИГПАН, 1992 г. -175 с.

11. Скловский, К. И. Собственность в гражданском праве / К. И. Скловский. - 5-е изд. - М. : Статут, 2010. $-893 \mathrm{c}$.

12. Субочев, В. В. Законные интересы / В. В. Субочев. - М. : Норма, 2008. - 496 с.

13. Суханов, Е. А. Лекции о праве собственности / Е. А. Суханов. - М. : Юрид. лит., 1991. - 239 с.

14. Честнов, И. Л. Постклассическая теория права : монография / И. Л. Честнов. - СПб. : АлефПресc, 2012. -650 c.

\section{REFERENCES}

1. Alekseev S.S. Obshchaya teoriya prava [General Theory of Law]: ucheb. 2-e izd. Moscow, Velbi Publ., Prospekt Publ., 2009. 565 p.

2. Alekseev S.S. Pravo sobstvennosti. Problemy teorii [The Right of Ownership. Problems of the Theory]. Moscow, Norma Publ., 2008. 239 p.

3. Dyugi L. Social'noe pravo, individual'noe pravo i preobrazovanie gosudarstva [Social Law,
Private Law and the Transformation of the State]. Moscow, 1909. 148 p.

4. Iering $\mathrm{R}$. fon. Interes i pravo [The Interest and the Right]. Yaroslavl, Tip. Gub. zem. upravy, 1880. $268 \mathrm{p}$.

5. Kamyshanskij V.P. Pravo sobstvennosti: predely $i$ ogranicheniya [Ownership: Limits and Limitations]. Moscow, Yuniti-Dana Publ., Zakon i pravo Publ., 2000. 303 p.

6. Kerimov D.A. Metodologicheskie funkcii filosofii prava [Methodological Functions of the Philosophy of Law]. Gosudarstvo i pravo [State and Law], 1995, no. 9, pp. 15-22.

7. Kuz'mina A.V. Kategoriya «interes» $v$ filosofii i prave [The Category of "Interest" in Philosophy and Law]. Moscow, Yuridicheskaya literarura Publ., 2009. $192 \mathrm{p}$.

8. Mal'ko A.V., Subochev V.V. Zakonnye interesy kak pravovaya kategoriya [Legitimate Interests As a Legal Category]. Saint Petersburg, Yuridichesky centr Press Publ., 2004. 359 p.

9. Mal'cev G.V. Social'nye osnovaniya prava [Social Grounds of Law]. Moscow, Norma Publ., 2007. $800 \mathrm{p}$.

10. Mozolin V.P. Pravo sobstvennosti v Rossijskoj Federacii $v$ usloviyah perekhoda $k$ rynochnoj ekonomike [Property Rights in the Russian Federation in the Context of Transition to a Market Economy]. Moscow, IGPAN Publ., 1992. 175 p.

11. Sklovskij K.I. Sobstvennost'v grazhdanskom prave [Property in Civil Law]. Moscow, Statut Publ., $2010.893 \mathrm{p}$.

12. Subochev V.V. Zakonnye interesy [Legitimate Interests]. Moscow, Norma Publ., 2008. 496 p.

13. Suhanov E.A. Lekcii o prave sobstvennosti [Lectures on Property Rights]. Moscow, Yuridicheskaya literatura Publ., 1991. 239 p.

14. Chestnov I.L. Postklassicheskaya teoriya prava: monografiya [Post-Classical Theory of Law]. Saint Petersburg, Alef-Press Publ., 2012.650 p.

\section{Information About the Author}

Andrey V. Ryzhik, Candidate of Sciences (Jurisprudence), Head of the Department of Criminal Law and Criminal Procedure, Vitebsk State University named after P.M. Masherov, Prosp. Moskovskiy, 33, 210038 Vitebsk, Belarus, asrupirant8381@mail.ru, https://orcid.org/0000-0001-6705-1679

\section{Информация об авторе}

Андрей Владимирович Рыжик, кандидат юридических наук, заведующий кафедрой уголовного права и уголовного процесса, Витебский государственный университет им. П.М. Машерова, просп. Московский, 33, 210038 г. Витебск, Беларусь, asrupirant8381@mail, https://orcid.org/0000-0001-6705-1679 